\title{
Educacão Infantil na Noruega
}

\author{
Early education in Norway
}

Eulina da Rocha Lordelo

Universidade Federal da Bahia

Monika Rothle

University

of Stavanger

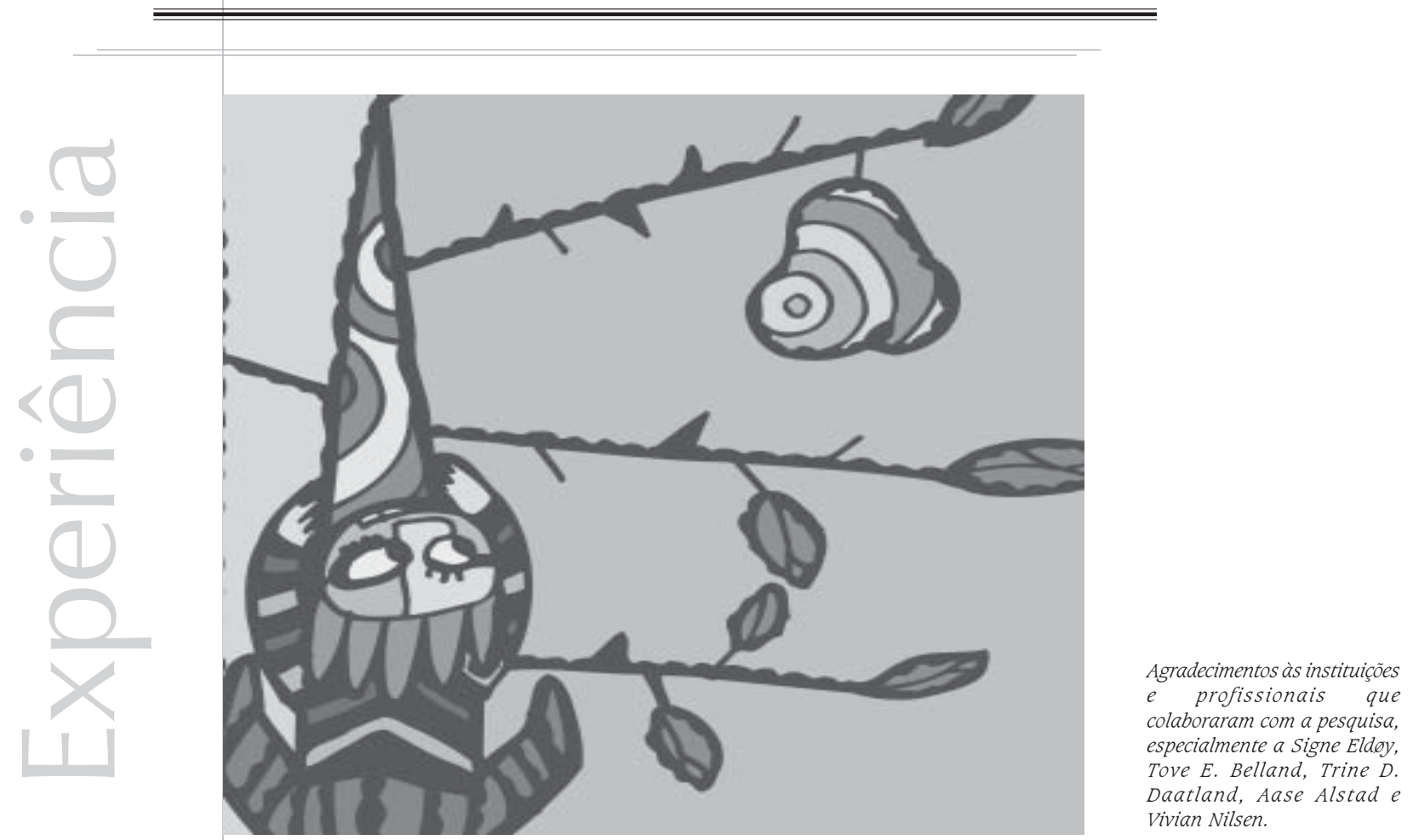


Resumo:Em comparação com os demais países nórdicos, a Noruega tem uma história mais recente de educação infantil. Um sistema disseminado e com forte financiamento público só se tornou disponível a partir dos anos 70. A descrição desse sistema de educação infantil contida neste artigo inclui um breve histórico, informações sobre financiamento, responsabilidades e custos, disposições legais sobre pessoal - formação necessária e condições de trabalho, bem como instalações, equipamentos e materiais. Todo o sistema é regulado por legislação nacional, preservando ampla liberdade de planejamento e ação para as próprias instituições e o pessoal envolvido. Os objetivos e metas, conteúdos e métodos, a pedagogia como idéias sustentadas e práticas assumidas constituem o foco central do artigo, especialmente a ênfase dedicada à brincadeira e ao trabalho criativo. Acompanhando o relato, o artigo propõe algumas comparações com a situação brasileira, enfatizando as diferenças legais, culturais e pedagógicas que podem ser observadas nos dois sistemas, buscando-se refletir sobre lições que podem ser extraídas e usadas na avaliação do sistema de educação infantil no Brasil.

Palavras-chave: educação infantil, currículo, brincadeira, cuidado com a criança.

Abstract: Compared with other Nordic countries, Norway has a more recent history in early child education. A broad system, with strong public support, only became available from the 70's. A description of this system in this paper includes a brief historic, information about funding, responsibilities and costs, legal regulations about personnel - education and work conditions, as well as facilities, equipment and materials. The whole system is guided and controlled by national regulations, although freedom for planning and acting is kept for institutions and personnel. Objectives and goals, contents and methods, the pedagogy as sustained ideas as well as actual practices constitute the central focus in this paper, especially the emphasis dedicated to play and creative work. We also make some comparisons with the Brazilian situation, emphasizing the legal, cultural and pedagogical differences observed in both systems. We use these comparisons to think about the lessons that can be learned and used in evaluating the early child education system in Brazil.

Key words: early child education, curriculum, play, childcare system.

Na fábula dos Irmãos Grimm, João e Maria são abandonados pelos pais porque o lenhador não tem comida suficiente para a família. A casinha que os atrai na floresta é feita de bolo e coberta com doces, mas a mulher que lhes oferece abrigo é uma bruxa malvada que deseja engordar os irmãos e comê-los. $\mathrm{Na}$ Noruega contemporânea, só a aparência de "casa de boneca" das creches evoca o conto de fadas. Os fantasmas da fome e do abandono das crianças foram deixados em um passado distante. As famílias sempre podem alimentar os filhos e, quando saem para trabalhar, podem deixá-los numa linda casa, cheia de brinquedos. A mulher que cuida de João e Maria é uma professora formada e tem a ajuda de outros jovens, a maioria mulheres, que se empenham em tornar suas vidas mais ricas, permitindo-Ihes brincar e oferecendoIhes desafios ao seu desenvolvimento. Assim é a educação infantil na Noruega.

\section{Uma visão histórica da educação infantil na Noruega}

O país tem alguma tradição de serviços de creches e pré-escolas desde o final do século XIX, mas a educação infantil só se tornou uma instituição social importante durante os anos 70, quando a maioria das crianças passou a freqüentar o jardim de infância desde os primeiros anos de vida. A primeira lei a estabelecer regras nacionais para o serviço data de 1975, e foi seguida por diversas outras regulamentações, que definiram o currículo, 
formação de pessoal, responsabilidades e financiamento. Entre estas últimas, destacase o Plano Nacional para as instituições de educação infantil e o currículo nacional para essa faixa etária, de 1996.

Todas as formas de educação infantil na Noruega são denominadas barnehage (a palavra norueguesa para jardim de infância). Houve razões ideológicas para o nome, que foi fixado em 1971. O projeto de lei propunha o termo pré-escola, mas os legisladores consideraram que o nome pelo qual o serviço seria conhecido era importante, uma vez que o nome costuma carregar significados que podem ser usados para modelar expectativas e modos de funcionamento. No caso, eles recusaram o termo pré-escola, porque não se desejava que as crianças de zero a seis anos fossem expostas a programas semelhantes a programas escolares (Bø, 1993). Desejava-se que o conteúdo do serviço enfatizasse mais a brincadeira e as atividades criativas, de acordo com as idéias de Froebel. É provável que essa orientação seja uma conseqüência da forte influência desse educador, primeiro na Europa e, mais tarde, em praticamente todo o mundo. Froebel foi, no século XIX, o criador dos jardins de infância na Prússia (hoje Alemanha), onde nasceu. Sua filosofia educacional é profundamente cristã (protestante) e é baseada numa concepção de homem como ser essencialmente produtivo e criativo, sendo a tarefa da educação possibilitar a expressão e o desenvolvimento da pessoa (Walsh \& Tufekei, 2001). Uma idéia central na pedagogia froebeliana é a de que o processo de educação envolve mais extrair do que adicionar ao homem habilidades e conhecimentos. Aceitando a existência de estágios desenvolvimentais, Froebel acreditava que a criança só deveria realizar atividades para as quais tivesse a maturidade necessária, o que implica uma concepção não diretiva de professor e ênfase na brincadeira como o principal contexto de aprendizagem. A metáfora da criança como uma planta, ambiente como um jardim e professor como um jardineiro teve sua origem em Froebel e, não obstante as diversas outras influências nos currículos noruegueses, permanece viva na cultura relacionada à criança e à idade préescolar (Rothle, 2001).

\section{Organização geral - financiamento, responsabilidades e custos para as famílias}

Há muitas formas de cuidado não maternal com a criança na Noruega. Creches familiares, creches privadas em instituições, jardins de infância em tempo parcial, creches públicas em instituições e creches privadas, não oficiais e não regulamentadas, geralmente em casas de famílias. Este artigo focaliza os "barnehagen", públicos ou privados, que funcionam como jardins de infância em sentido estrito e que são a forma dominante de cuidado com a criança de zero a seis anos na Noruega. Com exceção dos arranjos particulares em casas de família, todas as outras formas de cuidado são reguladas pelo Estado e recebem financiamento público, devendo seguir os mesmos princípios e regras fixados em lei (Bø, 1993).

Cuidar das crianças dessa idade é considerado uma tarefa da sociedade, embora como uma suplementação do papel da família, a quem é atribuída a principal responsabilidade (Ministry Of Children and Family Affairs, 1996). A educação infantil é uma das muitas formas de apoio social, financiado pelo Estado, às famílias com crianças pequenas. Um amplo leque de incentivos e suportes, como licença parental de um ano, ajuda em dinheiro, licenças para acompanhar crianças doentes, entre outras, é oferecido aos pais.

Na Noruega, a educação infantil é um assunto das políticas de família e do bem-estar social, embora o próprio serviço seja orientado pela 
lógica da educação. A responsabilidade por construir e operar centros é atribuída às prefeituras, que são também responsáveis por monitorar o cumprimento da legislação (Bø, 1993). Os pais devem pagar, pelo serviço, cerca de 2.750 coroas (perto de 500 dólares americanos, aproximadamente), o que representa um terço do custo total, sendo o restante financiado pelas prefeituras. No entanto, está em curso um plano para reduzir esse valor à metade, a ser implantado brevemente, provavelmente, a partir de 2006. Os valores pagos são reduzidos para estudantes, pais ou mães solteiros e pessoas vivendo em algum tipo de dificuldade financeira, de acordo com estritas prescrições legais.

O "barnehage" abre, em geral, das 7h30m às $16 \mathrm{~h} 30 \mathrm{~m}$, de segunda a sexta, durante todo o ano, excluindo-se os feriados comuns e os feriados longos (Páscoa e Natal). Horários diferentes podem ser seguidos conforme condições especiais locais. A legislação é explícita quanto à necessária proporção de crianças por adulto: de zero a três anos, um adulto por três crianças; de três a seis anos, um adulto por seis crianças (Ministry of Children and Family Affairs, 1997). Uma vez que a jornada de trabalho é de 37,5 horas por semana e que os professores têm uma reserva de quatro horas por semana para preparação e estudos, além de eventuais faltas por doenças e outros motivos válidos, nem sempre essas proporções adulto-criança podem ser mantidas estritamente. Por outro lado, nem todas as crianças permanecem no "barnehage" durante todo o tempo de funcionamento diário, de modo que parece haver sempre adultos em número suficiente para as necessidades das crianças. Os grupos de até três anos são formados por nove ou dez crianças, enquanto os grupos de crianças mais velhas têm o dobro desse tamanho. Em geral, todos os grupos dispõem de três adultos, um professor formado e dois assistentes (Bø, 1993). Não há muitas crianças de menos de um ano no "barnehage", uma vez que esse período é coberto pela licença de um ano concedida a um dos pais. Exceções comuns são crianças filhas de estudantes e crianças com necessidades especiais.

Pessoal - formação e condições de trabalho Todos os grupos devem ter, obrigatoriamente, um professor, com formação específica em educação infantil, realizada numa faculdade ou universidade, num departamento de Educação, por três anos. Os outros adultos que têm contato direto com a criança são assistentes, pessoas com educação secundária (nove anos de educação obrigatória na Noruega) e, eventualmente, cursos secundários com foco em trabalho social. No mais, há apenas um diretor que, às vezes, é responsável por dois "barnehagen", sendo os serviços de limpeza e manutenção prestados por equipes que não pertencem ao corpo permanente da instituição. De resto, esses serviços de limpeza são bastante simples, inexistindo aquelas práticas de faxinas diárias em profundidade. Todas as tarefas da creche, como levar crianças ao sanitário, arrumar os pratos na máquina e nos armários, arrumar objetos, vestir crianças, fechar a creche, são realizadas pelos professores e assistentes, inexistindo pessoal de escritório ou de almoxarifado, copeiras, cozinheiros, etc. $\mathrm{Na}$ pequena amplitude de salários vigentes na Noruega, onde os salários médios mais altos são cerca de duas vezes maiores do que os mais baixos (Statistik Sentral Byrå, 2005), os trabalhadores do setor da educação infantil situam-se num patamar médio inferior. Assistentes, professores e diretores recebem salários suavemente diferenciados, conforme o nível de instrução, função e experiência. $\mathrm{O}$ número de homens trabalhando em "barnehagen" é muito pequeno, e isso é visto como uma das deficiências do serviço no país, na medida em que se deixa de fornecer modelos igualitários de papéis de gênero.

\section{Instalações, equipamentos e materiais}

Geralmente, um centro é um prédio especialmente construído para a função de
Todas as tarefas da creche, como levar crianças ao sanitário, arrumar os pratos na máquina e nos armários, arrumar objetos, vestir crianças, fechar a creche, são realizadas pelos professores e assistentes, inexistindo pessoal de escritório ou de almoxarifado, copeiras, cozinheiros, etc. 
"barnehage", com uma aparência de casa comum, com uma arquitetura simples, seguindo o layout de residências familiares. As instalações são planejadas para receber entre 60 a 70 crianças. Um "barnehage" possui, geralmente, duas casas separadas no mesmo terreno, com equipamentos próprios destinados a cada casa (embora não haja obstáculos entre eles), destinados às duas faixas etárias em que o serviço é dividido, zero a três e quatro a cinco anos. Cada casa abriga dois grupos de crianças, com o pessoal correspondente, professores e assistentes.

Os prédios são ambientes planejados, seguros, claros e funcionais: sala grande, pequenos quartos, dois vestuários, banheiros e copa/cozinha (às vezes no mesmo ambiente das salas grandes). Mesas grandes, às vezes um pouco mais baixas do que o usual, cadeiras de madeira, estantes e armários são os equipamentos utilitários comuns. A aparência doméstica é visível na organização do espaço, como pode ser visto nas fotos abaixo, na figura 1:

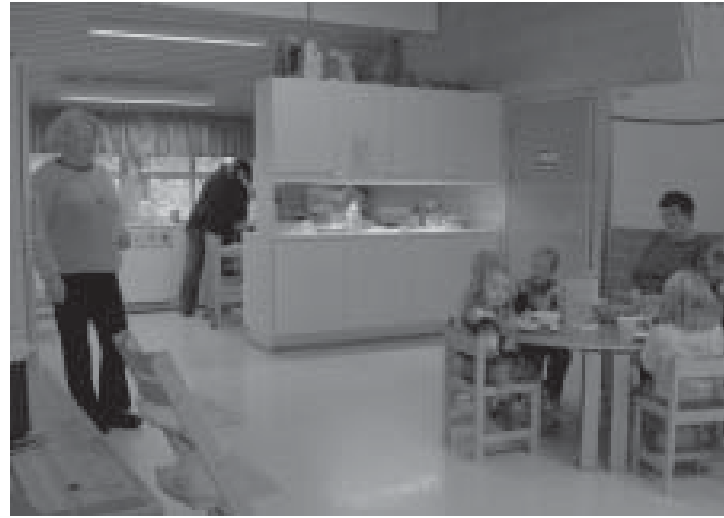

Refeições, estar e cozinha

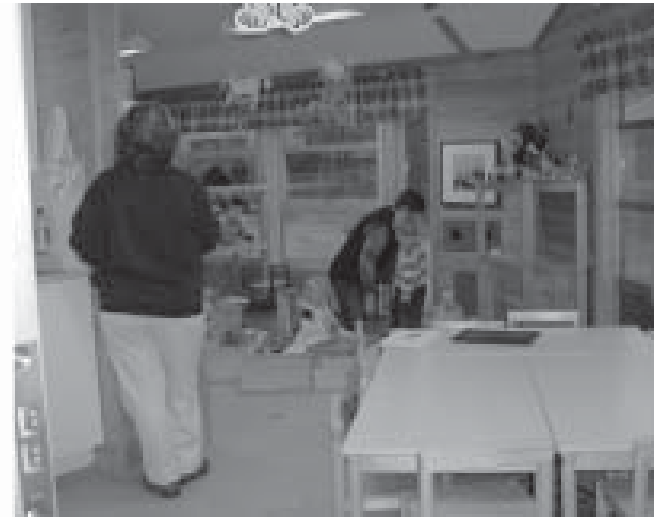

Estar: trabalho e lazer

Figura 1 - Lay-out dos espaços internos

Além disso, há vários móveis de brinquedo, como fogões, geladeiras e máquinas de lavar, que mobiliam pequenas salas ou "cantos" de brincar. Brinquedos, muitos de madeira, estão sempre disponíveis. Predominam os espaços delimitados, alguns sugerindo o tipo de atividade, como se vê nas imagens abaixo, na figura 2 :

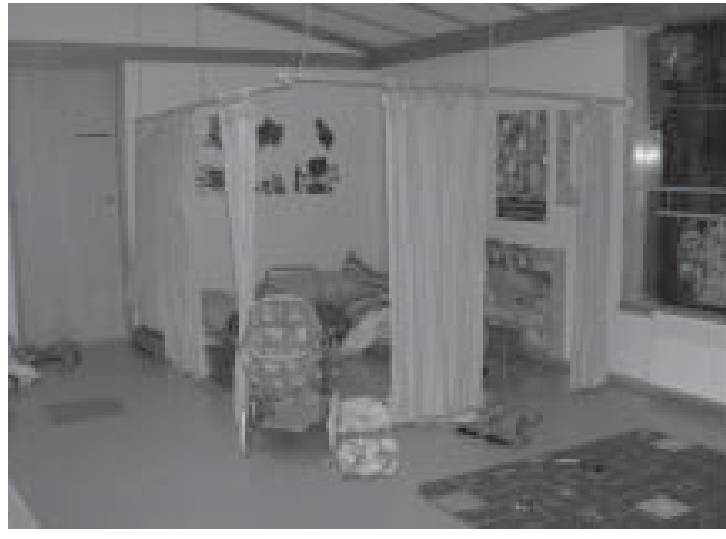

Cantinho delimitado por cortinas

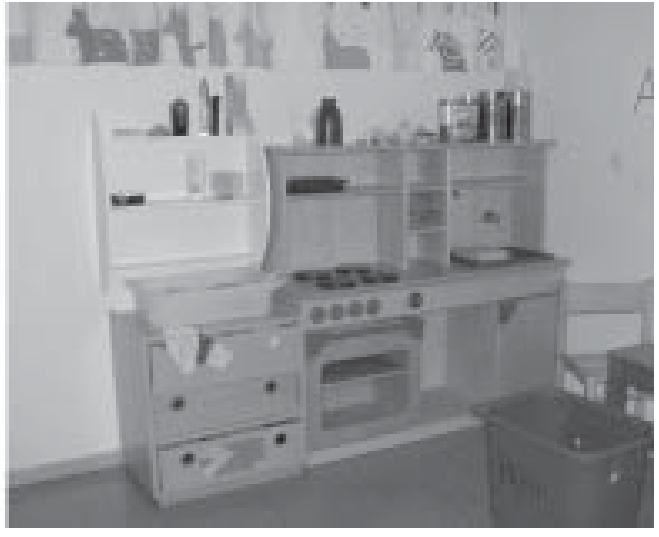

Miniaturas de móveis

Figura 2. Ambientes circunscritos 
As áreas externas dispõem de vários equipamentos para brincar: balanços, caixas de areia, escorregadeiras, entre outros. Alguns "barnehagen" dispõem de arranjos especiais para as áreas externas: labirinto de pedra, uma árvore caída, bancos semicirculares formando uma espécie de arena, redes de cordas, entre outros. Exemplos desses arranjos externos especiais podem ser vistos abaixo, nas figuras 3 e 4 :

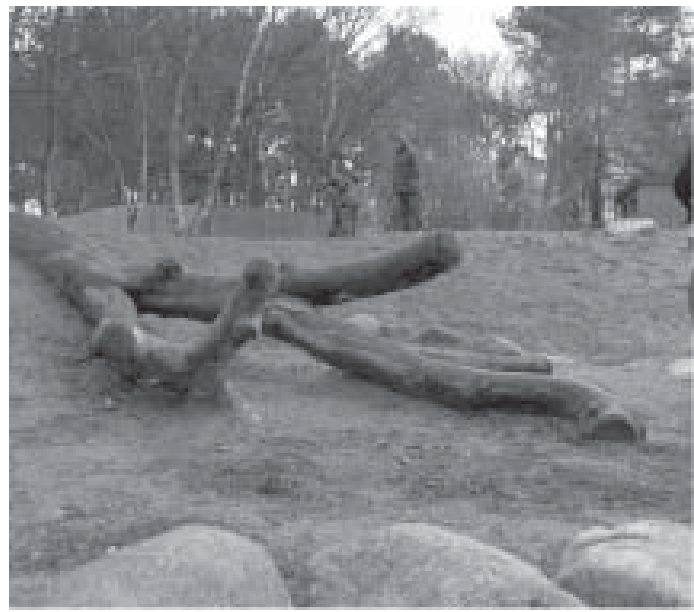

Árvore caída e arranjo de pedras

Figura 3- Ambientes externos "complexos"

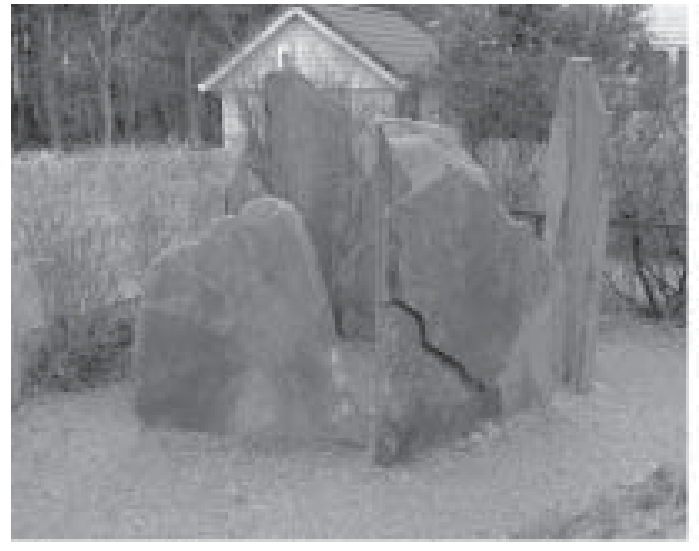

Pedras monumento

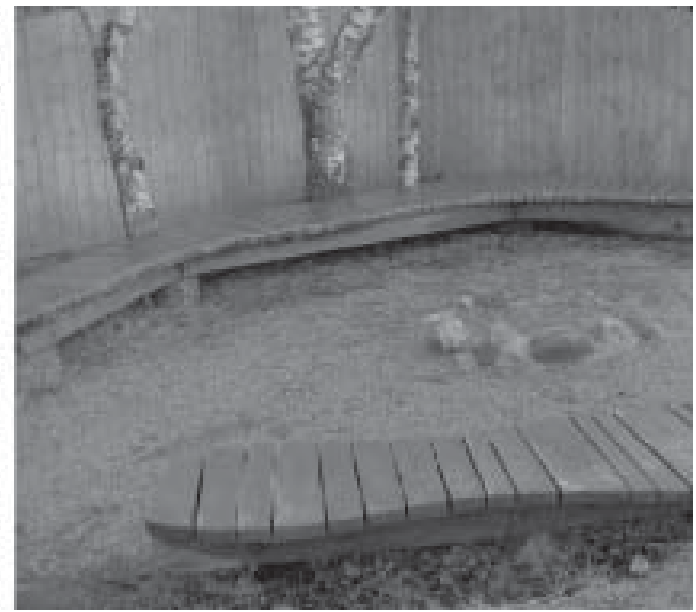

Espaço "assembléia"

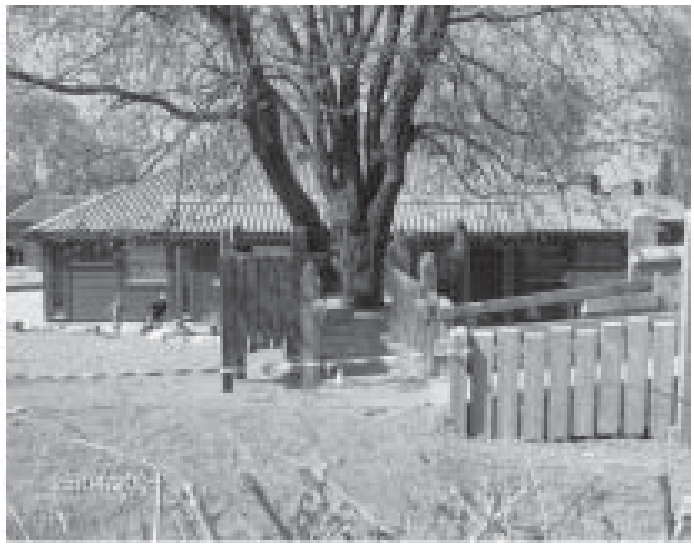

Pontes de madeira em torno da árvore

Figura 4 - Ambientes externos "complexos"

Velocípedes, bolas e carrinhos ficam nas diversas áreas e podem ser usados por todos. Materiais como argila, tinta, papel, cola, entre outros, também existem em quantidade e são usados regularmente.

\section{Principal finalidade, objetivos e metas - para quê é a educação infantil?}

Na Noruega, o sistema de educação infantil é pensado em duas perspectivas, explícitas na lei: a perspectiva dos pais, que devem trabalhar e, portanto, precisam de cuidado para os filhos; particularmente as necessidades do mercado de trabalho quanto ao trabalho das mulheres e o 
A pedagogia que sustenta as ações dos professores tem inspiração teórica eclética, muito distante de um campo teórico rígido. compromisso social de promover a igualdade entre homens e mulheres justificam todo o investimento social em educação infantil. A segunda perspectiva é a da criança, vista com um ser de direitos. Adotar essas duas perspectivas significa que a educação infantil existe para permitir o trabalho da mulher e para fornecer oportunidades para o desenvolvimento da criança (Ministry of Children and Family Affairs, 1996, 1997).

Há importantes implicações na adoção dessa dupla perspectiva. De um lado, o Estado subsidia fortemente o serviço e utiliza critérios socioeconômicos para alocar as vagas, que não são ainda suficientes para atender à demanda. Pessoas solteiras (pai ou mãe) têm prioridade no atendimento, bem como pessoas mais pobres, estudantes e crianças com necessidades especiais, visando a facilitar o engajamento dos pais no mercado de trabalho. De outro lado, há uma clara preocupação em não sobrecarregar a criança com exigências acadêmicas, em reconhecer o direito a uma infância mais livre e mais prazerosa, de modo que os objetivos educacionais, que traduzem a perspectiva do adulto, não devem sobrepujar os interesses e perspectivas da criança. Há um foco central em competência social, habilidades de vida social cooperativa, desenvolvimento de habilidades físicas, desenvolvimento emocional e auto-expressão. Segundo Alvestad (2003), uma orientação mais sociocultural caracteriza o currículo norueguês, em comparação com o currículo sueco, que privilegia uma orientação sociocognitiva.

O lugar secundário das habilidades acadêmicas no "barnehage" não significa falta de planejamento. Ao contrário, todo o sistema é regulado através de um conjunto de leis e instruções, embora não centralizadas, preservando-se muita liberdade para cada instituição e para cada professor e sua equipe. O Plano Nacional (o currículo), além de definir e fixar concepções e metas, fornece sugestões detalhadas de métodos, conteúdos e padrões de avaliação que devem ser usados. Cada "barnehage" tem um documento de planejamento anual, comunicado aos pais, especificando objetivos, atividades, responsáveis e datas, além de planejamentos semanais que orientam o trabalho no dia a dia. A participação dos pais nesse planejamento é encorajada.

\section{Conteúdo e métodos}

Cinco áreas de conteúdo devem ser trabalhadas: 1) Sociedade, religião e ética; 2 ) Valores e atitudes; 3) Estética; 4) Natureza, tecnologia e ambiente; 5) Atividade física e saúde (Ministry of Children and Family Affairs, $1995,1996)$. Durante o ano, cada uma dessas áreas deve ser alvo de ações pedagógicas, que devem ser realizadas como atividades iniciadas pela criança ou pelo professor, em situações formais e informais. Quanto mais velha é a criança, mais se admitem situações formais de ensino-aprendizagem, conduzidas pelo professor. Avaliações periódicas do desenvolvimento da criança são comunicadas aos pais e mantidas em registro. Uma vez que sejam detectados quaisquer problemas comportamentais ou de desenvolvimento, medidas de apoio são encaminhadas, como professores especiais, apoio do serviço social, sessões de aconselhamento com os pais, entre outras.

A pedagogia que sustenta as ações dos professores tem inspiração teórica eclética, muito distante de um campo teórico rígido. De modo geral, os professores têm conhecimentos em teorias contemporâneas de Psicologia do desenvolvimento e educação, mas estruturam seu trabalho combinando insights da pesquisa, objetivos sociais valorizados e tradições culturais. De fato, o currículo nacional enfatiza fortemente a transmissão da cultura nacional e local e os valores cristãos (Alvestad, 2003). Uma vez que os professores têm a liberdade de planejar seu trabalho, eles são os senhores de fato de suas escolhas. A lógica que se deduz das rotinas observadas e das conversas com os professores pode ser rastreada às idéias de Froebel, mas teorias contemporâneas de aprendizagem 
também servem de base à organização do trabalho. Alvestad (2004) menciona as tradições cognitivistas (Piaget), behavioristas (Skinner) e sociointeracionista (Vygostsky, Mead e Dewey), enriquecidas por experiências específicas mais contemporâneas, como as experiências das pré-escolas da Reggio Emilia.

De modo geral, as atividades proporcionadas, seja por iniciativa da criança ou do professor, são usadas para favorecer a descoberta e a exploração. Isso significa, de um lado, arranjar o ambiente e as atividades de modo a que a criança seja exposta a uma variedade de experiências, nas quais possa descobrir coisas novas e, de outro lado, convidar a criança a experimentar, tentar por si mesma e tornar-se consciente dos seus processos de descoberta. Espera-se que, nesse processo, a criança desenvolva sua motivação para a descoberta e a ação, bem como sentimentos de autoconfiança em suas habilidades de capacidade de aprendizagem.

A maioria das situações de ensinoaprendizagem ocorre em contextos de vida cotidiana, enquanto as crianças realizam suas atividades. Por exemplo, uma vez por semana, adultos e crianças preparam uma refeição quente, alguma coisa simples, como uma sopa. A escolha dos ingredientes, a compra, o preparo e o consumo são ocasiões para aprender algo sobre a natureza (o nome dos vegetais, de onde vêm, como são cultivados, em que época). A compra dos ingredientes numa loja próxima é ocasião para aprender sobre profissões, dinheiro, vizinhança. Mensurar os ingredientes - contar, pesar, dividir, fornece oportunidades para a realização de diversas operações lógico-matemáticas. Usar máquinas e instrumentos de cozinha permite abordar conhecimentos tecnológicos e adquirir destreza no seu manejo. Compartilhar as tarefas, servir e consumir a refeição proporcionam material para aprender sobre convivência e normas sociais e culturais. Qualquer atividade é ocasião para a aprendizagem de novas palavras e, principalmente, para o conhecimento e expressão de sentimentos, desenvolvimento da identidade e de uma auto-estima positiva. Há uma forte ênfase em atividades ao ar livre, no convívio com a natureza e no desenvolvimento de habilidades físicas. Nunca menos de uma vez por semana e, freqüentemente mais, os grupos saem do "barnehage" para um passeio num bosque próximo, independentemente do clima do dia. Observar os caminhos, as plantas, ouvir os ruídos da natureza - o vento, a água caindo subir em árvores, coletar produtos vegetais de todo tipo, são ocasiões ricas de situações de ensino-aprendizagem. Ademais, muito do tempo passado no "barnehage" é usado ao ar livre, no parque, em brincadeiras de todo o tipo, a maior parte delas sob controle da própria criança, que brinca em pequenos grupos, em duplas ou só. Os adultos ficam por perto, ajudam com alguma sugestão, disponibilizam objetos para as crianças mais novas e "vigiam" o aparecimento de algum conflito, interferindo quando necessário. Eles não brincam com as crianças, de fato, assumindo mais o papel de encorajar atividades e alianças.

Essa ênfase em natureza é bastante coerente com a cultura norueguesa em geral (Gullestad, 1992), e também com a tradição froebeliana do jardim de infância, que confere ao contato com a natureza um importante papel na educação do homem (Walsh \& Tufekei, 2001). Essa ênfase constitui uma das marcas características da educação infantil no país. Outra marca distintiva é a fidelidade às tradições culturais concernentes a áreas como mitologia nórdica, literatura nacional, inclusive a popular, e arte. Canções, rimas, mitos, contos de fadas, artes plásticas, entre outras manifestações, são o material do dia a dia no "barnehage", inclusive nos materiais didáticos. Evidências dessa profunda imersão no contexto cultural regional podem ser entrevistas no envolvimento geral de adultos - professores, assistentes, pais e eventuais visitantes nas atividades de canto e música que ocorrem freqüentemente no "barnehage": todo mundo conhece as brincadeiras e canções utilizadas, uma vez que muitas delas foram recolhidas da cultura popular.
A maioria das situações de ensinoaprendizagem ocorre em contextos de vida cotidiana, enquanto as crianças realizam suas atividades. Por exemplo, uma vez por semana, adultos e crianças preparam uma refeição quente, alguma coisa simples, como uma sopa. 
Ademais, não há muita preocupação com desempenho estritamente escolar. Não é esperado que a criança seja preparada para a escola, no sentido de que tenha conhecimento do alfabeto, seja capaz de escrever palavras ou letras. Os professores relatam que as crianças, ao final do período, costumam reconhecer o seu nome e contar até 10. No entanto, esse tipo de habilidade não é avaliado sistematicamente, uma vez que está fora do âmbito da educação infantil. Familiaridade com sons, conceitos de quantidade, percepção de formas, entre outras, são as aquisições desejadas. Por outro lado, espera-se que a criança seja capaz de conviver com outras crianças e adultos cooperativamente, que saiba comunicar desejos, necessidades e emoções, que tenha desenvolvido uma identidade positiva e que seja capaz de reconhecer e solidarizar-se com as necessidades e sentimentos dos outros. Paralelamente, domínio do corpo, coordenação motora, força e destreza são enfatizados.

A preparação para a escola (a criança entra na escola obrigatória no ano em que completa seis anos) consiste de familiarização com o contexto e aceitação da mudança próxima. Os professores programam visitas à futura escola para o conhecimento das instalações e dos futuros professores. A preparação para a escola é tratada como uma transição etária, uma promoção para uma nova fase da vida, com os significados simbólicos associados (crescer, ficar mais responsável, mais esperto).

\section{Rotinas}

A maior parte das crianças chega por volta das 8 horas da manhã. Depois de tirar casacos e trocar sapatos, elas brincam livremente em qualquer atividade de sua escolha. O café da manhã acontece entre $8 \mathrm{~h} 30 \mathrm{~m}$ e $9 \mathrm{~h}$. Adultos e crianças tomam juntos o café, que consiste em refeições enviadas de casa pelos pais ou itens comprados pelo "barnehage", pagos pelos pais: pão, leite, iogurte, geléia, queijo, pepino, tomate. O clima é muito familiar, bem distante de um refeitório institucional. Enquanto se retira a mesa e se arrumam os pratos e sobras de comida, as crianças ocupam-se de suas brincadeiras. Alguma atividade de contar história, cantar, rimas e poemas tradicionais costuma ocorrer nessa parte do dia. Um pouco mais tarde, as crianças são preparadas para o tempo ao ar livre que, em geral, não envolve atividades conduzidas pelo adulto. Meio-dia é hora do almoço, que repete aproximadamente o café da manhã (de acordo com os hábitos da população norueguesa, que costuma fazer uma refeição rápida nesse horário, constando quase sempre de sanduíches). Esse lanche é seguido pelo descanso, principalmente para as crianças mais jovens. As demais se ocupam de atividades mais sossegadas, geralmente nas salas, como olhar revistas e montar objetos. Esse horário é aproveitado pela maioria dos adultos para um descanso de meia hora, numa sala separada. O resto da tarde é dedicado à brincadeira ao ar livre, até a hora, bastante variável, em que os pais vêm pegar as crianças. A principal refeição do dia, o jantar, é feita com a família.

Essa rotina básica é complementada com os inúmeros passeios organizados, em dias passados no bosque, visitas a museus, bibliotecas e lugares agradáveis pelas redondezas. Alguns "barnehagen" organizam sistematicamente grupos natureza, ou seja, excursões com propósitos educacionais, para trabalhar temas específicos, por exemplo, trânsito, plantas, sociedade.

Datas cristãs ou nacionais também marcam a vida da criança no "barnehage". Natal, Páscoa e Independência nacional são comemorados intensamente, com atividades preparatórias que duram vários dias e que podem envolver desfiles e festas, visitas a igrejas, lojas, exposições, dezenas de oportunidades de sair do "barnehage" e misturar-se com a vida cotidiana da comunidade.

\section{Refletindo sobre o "barnehage"}

Como um dos países mais ricos do mundo, a Noruega tem oferecido às famílias e às suas 
crianças um amplo leque de benefícios que encorajam as mulheres a ter filhos e a trabalhar simultaneamente. O sistema de educação infantil, embora pago e não disponível para todo mundo, é planejado conscienciosamente, tendo como base os interesses e direitos da criança e, não menos importante, valores e metas da cultura, como a igualdade entre homens e mulheres, a identidade e cultura nacionais e a promoção da tolerância.

Entrar num "barnehage" é uma experiência agradável e enriquecedora. A impressão geral é de um contentamento tranqüilo, em que a motivação de cada criança encontra uma resposta, seja de pares compartilhando os mesmos interesses, seja de adultos apoiadores, responsivos, que guiam as crianças minimamente, mas fornecem os modelos e as contingências para a socialização em conformidade com a cultura e os valores.

Sem dúvida, um dos aspectos mais relevantes do sistema é o seu foco no brinquedo livre e nas atividades criativas, apoiado por uma pedagogia estruturada em atividades cotidianas. Muitos aspectos do serviço oferecido na Noruega dependem do alto investimento governamental no setor, além do pagamento realizado pelas próprias famílias. Nesse sentido, trata-se de quanto valor social a sociedade está disposta a atribuir ao serviço, traduzindo-se em investimento concreto, e quais os recursos efetivamente disponíveis para tal. As proporções no número de adultos por criança, conjugadas aos bons salários pagos aos trabalhadores, implicam um serviço bastante caro, mesmo pelos padrões de qualquer país rico.

Como tal, é impossível pensar nesse sistema como modelo a transportar para outros contextos, ainda que qualquer transporte de modelo pudesse ser efetivo. O horário de funcionamento das instituições é muito adequado para um país em que a maioria dos trabalhadores encerra seu horário de trabalho às $16 \mathrm{~h}$ e em que o trabalho em turnos parciais é tão comum, mas, certamente, não funcionaria bem num país em que as jornadas de trabalho são longas e em que a maioria das pessoas que precisam do serviço vive em grandes cidades, gastando muitas horas do dia em trânsito.

Entretanto, restam ainda muitas características que são independentes de quanto dinheiro se dispõe para investimento. Sem dúvida, as mais importantes são o foco no brinquedo, nas atividades criativas e na inserção das situações de ensino-aprendizagem na vida cotidiana. Uma vez que a entrada da criança na escola se dá muito cedo, há uma forte separação entre as duas instituições, um assunto que é motivo de debates entre os professores dos dois níveis.

De fato, a identidade da educação infantil norueguesa pode ser vista como um processo em construção. Enquanto a geração de professores mais velhos tende a ancorar o conceito de "barnehage" ao de casa, os professores formados há menos tempo tendem a ver a instituição como mais aparentada ao campo educacional. Mas a vinculação ao campo educacional não significa adesão ao modelo escolar de transmissão de conhecimento do adulto para a criança. Em vez disso, o processo educacional está mais identificado com o desenvolvimento da criança, visto como apoiado, e não produzido, pelo adulto. Há uma consciência disseminada de que um jardim de infância não é uma escola e tampouco o substituto da casa da criança, o que pode ser visto em todos os momentos, seja na configuração do espaço, seja nas atividades programadas, seja na relação estabelecida entre famílias, crianças e profissionais. Não sendo casa, não sendo escola, o conceito, a estrutura e o funcionamento da instituição mantêm-se numa posição eqüidistante desses dois campos, tentando afirmar uma identidade própria.

Essa busca por uma identidade própria pode ser uma das maiores contribuições do sistema de educação infantil norueguês para o mundo. Além disso, a preocupação com o respeito à perspectiva da criança, em harmonia com os interesses dos pais e da sociedade, constitui o "barnehage" como um experimento social que, independentemente de suas repercussões em longo prazo, pode representar uma inspiração para as sociedades e, em particular, profissionais e formuladores de
Enquanto a geração de professores mais velhos tende a ancorar $\mathrm{O}$ conceito de "barnehage" ao de casa, os professores formados há menos tempo tendem a ver a instituição como mais aparentada ao campo educacional. 
políticas públicas, na busca do bem-estar da criança.

O conhecimento e a convivência com as instituições de educação infantil na Noruega remetem inevitavelmente à comparação com a realidade brasileira. Nesse campo, as diferenças, mais que as semelhanças, atraem o olhar do observador. No caso brasileiro, não se pode falar em um sistema de educação infantil, seja considerando as regulamentações, seja considerando a filosofia, os recursos, e, em último caso, a cultura em torno do tema.

Em primeiro lugar, prevalece no Brasil uma clara diferenciação na organização e funcionamento de creches e pré-escolas. Embora a nova LDB tenha estabelecido a denominação de educação infantil para a faixa etária de zero a seis anos e reservado os termos creche para a faixa etária de até três anos e pré-escola para a subseqüente (Brasil, 1996), na prática, as estruturas dessas instituições permanecem claramente distintas. Além disso, a variabilidade existente nas instituições brasileiras supera em muito todas as diferenças existentes na Noruega.

Também não há, no Brasil, um consenso social acerca do arranjo ideal para atender à criança de zero a seis anos. A freqüência a uma instituição de tempo integral ainda é mais comum entre as famílias onde as mães precisam trabalhar e não dispõem de outros meios de cuidar das crianças. Outro aspecto importante a distinguir as situações norueguesa e brasileira na área de educação infantil é o alto investimento social e governamental nessa faixa etária, devido às características do mercado de trabalho nacional. Na Noruega, o trabalho das mulheres é rigorosamente necessário, em vista da economia em crescimento e da baixa densidade populacional (Statistik Sentral Byrå, 2004), uma situação bem diferente da brasileira, onde uma vasta proporção da população adulta vive no desemprego ou no subemprego. Aqui, seja pela escassez geral de recursos, seja pela baixa prioridade à área, não há dinheiro suficiente alocado para essa faixa etária, e é muito baixo o investimento social para gerar tecnologias, materiais e equipamentos adaptados para o contexto, bem como a valorização social traduzida em salários e vantagens profissionais (Rosemberg, 2002; Kishimoto, 1999).

Além disso, o atendimento à criança de zero a seis anos no Brasil vem sendo concebido, nos últimos anos, como assunto da área de educação, com todas as conseqüências decorrentes. Possivelmente, em função de a história da assistência social no Brasil estar associada a práticas de caridade, clientelismo político e controle social e ideológico, tem se caminhado para negar o papel assistencial do atendimento à criança dessa idade, o que pode contribuir para uma visão restrita do serviço oferecido, desvinculado de outras políticas públicas que são igualmente importantes para a saúde, o bem-estar e o desenvolvimento da criança e de suas famílias. E finalmente, associadas a essa última característica, as expectativas sociais, talvez apoiadas por teorias pedagógicas de maior prestígio no Brasil, atualmente conferem um alto valor ao desenvolvimento de habilidades cognitivas e ao papel dominante do professor em desenvolver essas habilidades. De modo geral, a função de preparação para a escola é muito importante na educação infantil, o que se reflete nas orientações curriculares para a área (Brasil, MEC/SEF, 1998). Essa orientação é visível nas instituições públicas de educação infantil brasileiras, que são, em geral, organizadas à imagem e semelhança da escola de primeiro grau, com carteiras voltadas para o professor, material escolar tradicional e tarefas para casa. Não obstante as diferenças em contexto e condições materiais que existem entre Brasil e Noruega, podemos extrair algum ensinamento a ser empregado em nossa própria realidade? Como já mencionado acima, não é provável que possamos transplantar o modelo de um contexto para outro, sob risco de graves distorções. Entretanto, o conhecimento de outros modelos, a análise de sua congruência com a realidade socioeconômica, demográfica, política e cultural trazem uma contribuição imediata, que é a ativação de nosso senso crítico para avaliar nossas decisões e tradições. Por exemplo, o processo de transferência do atendimento à criança de zero a seis anos para a área da educação e o seu 
afastamento do campo da assistência social pode ser repensado, uma vez que estamos assistindo à evolução das concepções sobre assistência, que vêm sendo crescentemente vistas como políticas de desenvolvimento, com fortes repercussões econômicas, sociais e ideológicas. Os diversos programas de assistência social em curso no País têm caminhado para deslocar as práticas de assistência para o campo dos direitos sociais, que fortalecem a cidadania, em vez de anulá-la. Outro exemplo importante de possível contribuição da educação infantil norueguesa para o sistema brasileiro encontra-se no foco na brincadeira como principal meio de desenvolvimento da criança, o contato com a natureza e a valorização da cultura popular, entre outros.

\section{Concluindo}

Casas de boneca e fadas-madrinha? Bom, a educação infantil norueguesa não é realmente um conto de fadas. Não há mágica que substitua o intenso investimento social em dinheiro, idéias, planejamento e trabalho duro. Ademais, tensões, contradições e incoerências estão presentes no dia a dia da instituição, nos debates entre especialistas, famílias, formuladores de políticas e profissionais. Problemas não resolvidos permanecem como desafios, definindo o "barnehage" como instituição aberta, em permanente construção. Por isso mesmo, a instituição pode ser um interlocutor útil no diálogo com outros contextos, culturas e países. Enquanto isso, naturalmente, a história de João e Maria continua mantendo seu apelo na imaginação de todos nós.

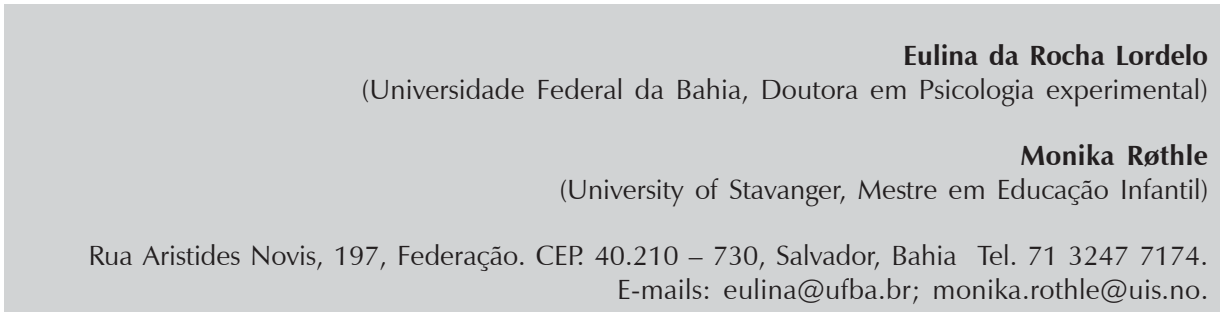

Recebido 25/11/05 Reformulado 27/04/06 Aprovado 23/06/06

ALVESTAD, M.. Preschool Teachers' Understanding of some Aspects of Early Childhood Curricula in Norway and Sweden. In Research in Early Childhood Education, vol. 6. New Zealand: 2003, pp. 51-64.

ALVESTAD, M. Preschool Teachers' Understanding of some Aspects of Educational Planning and Practice Related to the Nacional Curricula in Norway. International Journal of Early Education, vol. 12, n. 2. 2004, pp. 83-97.

$B \varnothing$, I. Norway. In M. Cochran (org.). International Handbook of Childcare Policies and Programs. Westport: Greenwood Press, 1993, pp.391-413.

BRASIL. Lei de Diretrizes e Bases, 1996

BRASIL. MEC/SEF. Referencial Curricular para a Educação Infantil Brasilia: MEC/SEF, 1998.

GULLESTAD, M. The Art of Social Relations. Essays on Culture. Social Action and Everyday Life in Modern Norway. Oslo: Scandinavian University Press, 1992.
KISHIMOTO, T. M. Política de Formação Profissional para a Educação Infantil: Pedagogia e Normal Superior. Educação e Sociedade, vol. 68. 1999, pp. 61-79.

MINISTRY OF CHILDREN AND FAMILY AFFAIRS. Framework Plan for Day-Care Institutions. Oslo: Q-0903 B, 1995.

MINISTRY OF CHILDREN AND FAMILY AFFAIRS. Framework Plan for Day-Care Institutions: a Brief Presentation. Oslo: Q-0917, 1996.

ROSEMBERG, F. Organizações Multi-laterais, Estado e Políticas de Educação Infantil. Cadernos de Pesquisa, vol. 115. 2002, pp. 25-63.

Rothle, M. Skjulte Forbilder. Barnehagefolk/utgitt av Pedagogisk Forum, vol. 17 (4). 2001, pp. 48-59.

STATISTIK SENTRAL BYRÅ. Dados sobre a Noruega 2004. http:// www.ssb.no/english/subjects/00/minifakta en/po/.Consulta realizada no dia 16 de junho de 2005.

Walsh, D.J., Shung, S. \& Tufekei, A. Friedrich W. Froebel-1782-1852. In J.A. Palmer (org.). Fifty Major Thinkers on Education: from Confucius to Dewey. Londres: Routledge, 2001, pp.94-96.
Referências 